\title{
Prevalence of small for gestational age newborns and associated factors in a Brazilian Northeast capital
}

\author{
Micaely Cristina dos Santos Tenório 1 \\ Marilene Brandão Tenório 2 \\ Raphaela Costa Ferreira 3 \\ Carolina Santos Mello 4 \\ Alane Cabral Menezes de Oliveira 5
}

1-3,5 Faculdade de Nutrição. Universidade Federal de Alagoas. Campus A.C. Simões. BR 104 Norte, Km 96,7. Tabuleiro dos Martins. Maceió, AL, Brasil. CEP: 57.072-970. E-mail: alanecabral@gmail.com

${ }^{4}$ Escola de Nutrição. Universidade Federal da Bahia. Salvador, BA, Brasil.

\begin{abstract}
Objectives: to analyze the factors associated with the birth of small for gestational age (SGA)infants, in a Northeastern Brazilian capital.

Methods: a cross-sectional study was carried out with 331 pregnant women and their newborns attending the public health network in the city of Maceio, in 2014. Maternal antenatal data were collected (socioeconomic, lifestyle, clinical and nutritional) as well as data of the newborns (gestational age, mode of delivery, sex, birth weight and length), after delivery. Birth weight was classified according to the INTERGROWTH-21st curves, being considered SGA those below the 10th percentile according to gestational age and gender. The results were analyzed by Poisson regression using a hierarchical model and were expressed as prevalence ratios (PR) and their respective 95\% confidence intervals (C195\%).

Results: it was verified that $5.1 \%$ of the newborns were SGA. Regarding the associated factors, after adjustment of the hierarchical model, the variable working outside the home was associated with the endpoint studied [PR $=0.14 ;(C I 95 \%=0.02-0.75) ; p=0.022]$.

Conclusions: it was verified a low frequency of SGA infants in the evaluated population. The fact that the mother works outside the home proved to be a protective factor for this condition.
\end{abstract}

Key words Birth weight, Risk factors, Protective factors 


\section{Introduction}

Birth weight is an isolated parameter for the determination of infant's immediate and future health conditions. Children who are born small for gestational age (SGA), besides being at imminent risk of developing problems in the neonatal period, are more propitious in adulthood to development of chronic diseases, including cardiovascular diseases, diabetes mellitus, systemic arterial hypertension and others. ${ }^{1-3}$

In this sense, a great part of the studies on the subject are related to the evaluation of newborns with birth weight lower than $2.500 \mathrm{~g}$, considered as low birth weight (LBW), on the other hand, the research involving the classification of SGA are limited because the information about the gestational age at birth 1 is necessary and this information is often under-reported.

The classification of SGA newborns is based on the distribution of birth weight for gestational age according to fetal growth curves. Currently, the World Health Organization (WHO) recommends that children whose birth weight is below the 10th percentile for gestational age and gender should be considered SGA, based on the reference population of Villar et al. 4

Some risk factors have been described as associated with birth SGA. Among them, it is worth highlighting the biological, cultural and socioeconomic factors, in which the developed countries present a lower prevalence when compared to developing countries. However, the incidence of SGA can vary according to definition criteria and due to the configurations of normality curves. $5-7$ In this context, the multicentric origin of the new growth curves, ${ }^{4}$ developed from data from different countries, including Brazil, is more representative in regards of our population, and can provide more accurate data on the prevalence of SGA newborns.

Considering that in this moment there are no national studies in the literature that address the prevalence of SGA newborns with the use of new growth curves and the scarcity of studies on the subject involving the short-term and long-term health consequences, the present study aims to evaluate the prevalence and factors associated with the birth of SGA newborns in a Brazilian Northeast capital.

\section{Methods}

A cross-sectional study carried out with pregnant women and their newborns attended by the public health network of the municipality of Maceió, capital of the state of Alagoas, in the year 2014. This study is part of a larger study for the Unified Health System (SUS) "Nutritional status, weight gain and feeding behavior of pregnant women from MaceióAlagoas: impact on the health of the mother-child binomial".

During the study period the city of Maceió was strategically organized in 8 health districts, with a total of 60 Basic Health Units (BHU). The selection of the population studied was based on the random draw of $50 \%$ of the BHUs total, per health district, using the list provided by the Municipal Health Department. All the pregnant women registered in each drawn up unit composed the sample, those units with more registered pregnant women contributed proportionally with a greater number of pregnant women in the sample.

The sample size calculation was carried out afterwards with the Epi Info version 7.0 program, considering a SGA prevalence of $12.0 \%, 6$ a sample error of $5 \%$ and a confidence interval of $99 \%$, requiring 281 mother-newborn dyads. However, due to the availability of resources, 331 pregnant women and their children were studied.

The inclusion criteria were pregnant with a single fetus, pregnant women living in the city of Maceió and followed up in the municipal public health network. Neonates with congenital diseases or those with neonatal intercurrences were excluded. Initially, the recruitment of pregnant women was performed, which occurred in a random manner on the days established for the prenatal consultations in the UBS, where the data for the survey were also collected. A standardized questionnaire previously tested by the research group, including socioeconomic data: age ( $\leq 15$ years / 16-19 years / 20-34 years $/ \geq 35$ years), degree of schooling $(\leq 4$ years of study / $>4$ years of study), income $(<1$ minimum wage / month / $\geq 1$ minimum wage / month, minimum wage $=174.66 \$$ ), marital status (single / married); (yes / no), smoking status (yes / no), sexually transmitted disease (yes / no), current nutritional status [low birth weight (yes / no) yes / no), eutrophic (no / yes), overweight (yes / no), inadequate food intake [energy and macronutrients (carbohydrates, proteins and lipids)].

At the moment of the interview, the variables weight and height were measured using a digital scale (Marte $\mathrm{LC} 200^{\circledR}$ ) and portable stadiometer, used to calculate the Body Mass Index (BMI), considering the established cut-off points by Atalah Samur et al. 8 Weight and pre-gestational BMI were also investigated, according to the referred data, as 
well as weight gain during pregnancy adjusted for gestational age, the latter being evaluated according to recommendations of the Institute of Medicine $(\mathrm{IOM})^{9}$ for weight gain agreement with the pregnant trimester.

For the evaluation of food consumption, two 24hour dietary recalls ( $\operatorname{Rec} 24 \mathrm{~h}$ ) were applied to each pregnant woman, the first one at the time of application of the survey questionnaire and the second one obtained by telephone, done at intervals of up to one month after initial collection. Rec $24 \mathrm{~h}$ were analyzed through the nutritional prescription and evaluation system (Avanutri $4.0^{\circledR}$ ), with subsequent adjustments of calories and macronutrients by the EAR (Estimated Average Requirement) ${ }^{10}$ method as cutoff point. The evaluation of the adequacy of food consumption was based on the recommendations for pregnant women according to the Dietary Reference Intakes (DRIs). 11

The data of the newborns were collected after delivery by the Registration System of the Municipal Health Department.

Birth weight was classified according to the new INTERGROWTH- 21 st curves, 4 considering cutoff points in percentiles according to international standards, where infants weighing below the $10^{\text {th }}$ percentile were classified as small for gestational age (SGA); those between the $10^{\text {th }}$ and $90^{\text {th }}$ percentiles, classified as appropriate for gestational age (AGA); those weighing above the 90th percentile, as large for gestational age (LGA), according to sex. The same cut-off points for the classification of birth length were considered.

Regarding the classification of gestational age at the time of delivery, were considered preterm those born with gestational age less than 37 weeks, term those with gestational age between 37 and 42 weeks, and post term those with gestational age equal to or greater than gestational age to 42 weeks. 12

Data were processed using the Stata application version 13.0. The Poisson regression was used in a hierarchical model with robust estimation of the variance, aiming to identify unfavorable factors to the birth of SGA, expressed in a dichotomous way.

Initially, univariate analyzes were performed, in which the independent variables that presented statistical association considering $p<0.20$ were selected to compose the multivariate regression model. The multivariate analysis was performed considering the construction of a conceptual model on birth weight determinants, adapted from Monteiro et al. 13 containing three hierarchical levels (Figure 1), in the following order: distal level (age, schooling, monthly family income, marital status and work outside the home); intermediate level (prior problems, smoking and / or alcohol use in pregnancy, sexually transmitted disease, current nutritional status and inadequate food intake) and proximal level (route of birth delivery).

The variables at the first hierarchical level were analyzed together, and variables with a significance greater than or equal to $p \geq 0.20$ were progressively excluded. Then, the variables of the second hierarchical level were added to the model and proceeded in the same way, with progressive exclusion of the variables of that level with a value of $p \geq 0.20$. In this way, all hierarchical levels were analyzed. For the control of possible confounding factors, variables with $p<0.20$ values were maintained in the models at each hierarchical level.

Finally, the magnitude of the associations between the outcome variable and the independent variables were expressed in the prevalence ratios $(\mathrm{PR})$ and their respective $95 \%$ confidence intervals (CI95\%), being considered significant $p<0.05$.

\section{Results}

331 mother-newborn dyads were studied. For the pregnant women, regarding socioeconomic data, $23.3 \%$ of mothers were adolescents, $7.5 \%$ were aged $\geq 35$ years; $5.4 \%$ had less than 4 years of study; $6.9 \%$ had monthly family income $\leq 1$ minimum wage; $29.0 \%$ reported working outside the home; $7.8 \%$ were smokers; $13.0 \%$ alcoholics and $1.5 \%$ had some STD. Regarding nutritional status, $17.0 \%$ were underweight and $40.9 \%$ were overweight. As regards to food intake, $79.4 \%, 80.3 \%, 61.9 \%$ and $0.03 \%$ of pregnant women respectively presented inadequate energetic, protein, lipid and carbohydrate intake.

Regarding the newborns, $50.7 \%$ were males, presenting mean gestational age at birth of $38.88 \pm$ 1.86 weeks, ranging from 29 to 43 weeks, with mean birth weight of $3.23 \pm 0.56 \mathrm{Kg}$, being $42.6 \%$ born from cesarean delivery and $92.4 \%$, term. Regarding the classification of birth weight, $5.1 \%$ were born SGA and $11.2 \%$ were LGA Regarding the length at birth, $15.5 \%$ were born with low length compared to $13.4 \%$ with high birth length.

Regarding the associated factors with the birth of SGA in this study, after gross analysis: family income $\leq 1$ minimum wage $[\mathrm{RP}=0.99$; $(\mathrm{CI} 95 \%=$ $0.99-0.99) ; p=0.033]$; working outside the home $[\mathrm{PR}=0.15 ;(\mathrm{CI} 95 \%=0.02-1.14) ; p=0.067]$; presence of STDs $[\mathrm{PR}=4.07 ;(\mathrm{CI} 95 \%=0.66-25.14)$; $p=0.130]$; maternal overweight $[\mathrm{RP}=2.07$; $(\mathrm{CI} 95 \%$ $=0.80-5.32) ; \mathrm{p}=0.129]$ and inadequate caloric intake $[\mathrm{PR}=0.47 ;(\mathrm{CI} 95 \%=0.18-1.23) ; p=0.127]$. After 


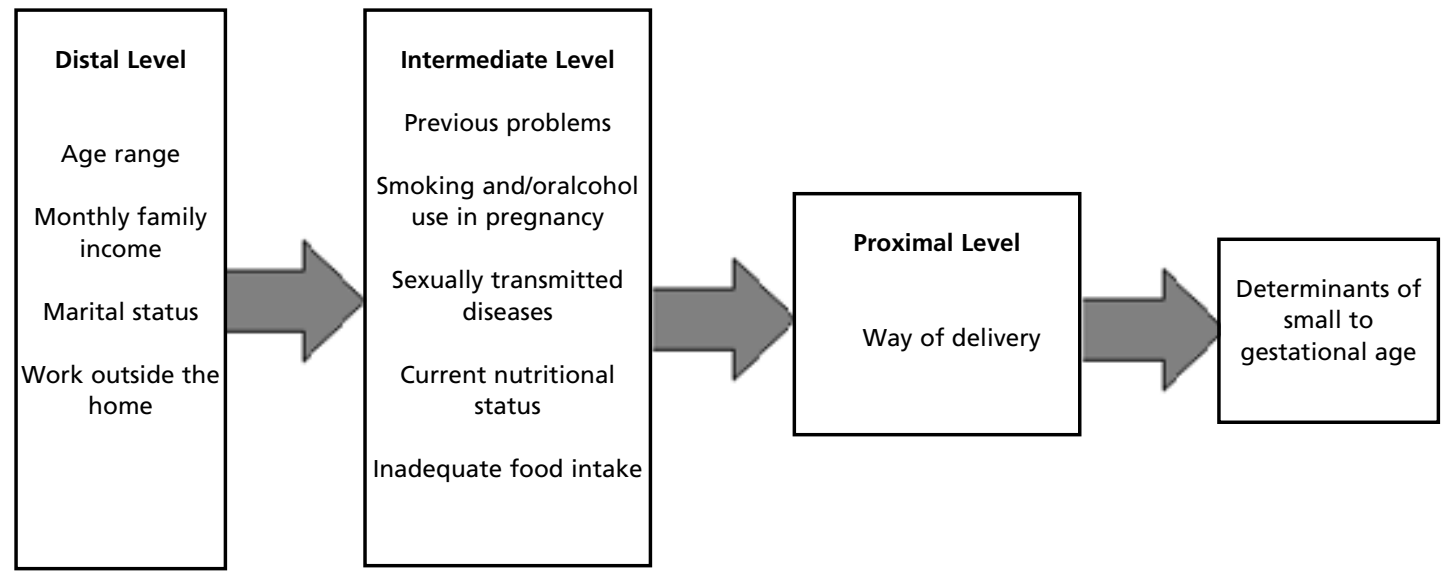

Source: Adapted from Monteiro et al.11

adjustment of the hierarchical model, only the variable work outside the home was associated with the outcome studied [PR $=0.14 ;($ CI95\% $=0.02-0.75)$; $p=0.022]$ (Table 1).

\section{Discussion}

The analysis of the prevalence and associated factors with the birth of SGA newborns is important for the screening of perinatal outcomes in the short and long term.1-3 In this study, the prevalence of SGA birth was $5.1 \%$ and was associated with the variable mother working outside the home.

The prevalence of SGA can be considered low when compared to other studies described in the international literature, which evaluated the prevalence of SGA considering the INTERGROWTH-2 $1^{\text {st }}$ curves, as a research done at the border of ThailandMyanmar (21.0\%)5 and another in Turkey (12.0\%). ${ }^{6}$

The INTERGROWTH-21st 4 curves were developed from a population-based multicenter study conducted in nine cities of different countries, including Pelotas (Rio Grande do Sul State) in Brazil, being the most suitable for the evaluation of the Brazilian population. Despite this, and since they have been available since 2014 , no national studies which have used this new curve for birth weight classification have been found, which makes it difficult to compare our findings.

On the other hand, some studies conducted in the country have evaluated the prevalence of SGA by other fetal growth curves, such as the study done in a public maternity hospital in São Paulo (17.9\%), 7 in five maternity hospitals in Rio Grande do Sul $(13.1 \%)^{14}$ and in a public prenatal service of a public maternity hospital in the Northeast (13.8\%).15 The authors also verified higher prevalence than those observed in the present study. The heterogeneity in the design of epidemiological studies is a frequently verified limitation, which makes it difficult to compare the results obtained.

Among the variables studied in this study, the fact that the pregnant woman worked outside the home was associated with the birth of SGA, acting as a protective factor. No similar findings were found in the literature considering fetal growth curves. On the other hand, some research related to LBW also found association with this variable, as in a study carried out in Italy aiming to assess the determinants of LBW, which also found a protective association between maternal activity outside the home and LBW. 16

Some factors could explain the influence of working outside the home as a protective factor for the birth of SGA newborns. Mothers who work outside the home feel more active and productive, in addition to having new interpersonal relationships which contribute to the maintenance of self-esteem, extrapolating the attribute of a housewife. In addition, working outside the home confers greater financial independence, contributing to the increase in family income, which may be related to a better maternal health condition. ${ }^{17}$ Another possible explanation would be that women who work outside the 
Association between independent variables and small for gestational age in the public health system of Maceió, Alagoas, Brazil, 2014.

\begin{tabular}{|c|c|c|c|c|c|c|}
\hline \multirow[t]{3}{*}{ Variables } & \multicolumn{2}{|c|}{ SGA } & \multirow[t]{3}{*}{ Gross PR (Cl95\%) } & \multirow[t]{3}{*}{$p^{*}$} & \multirow[t]{3}{*}{ Adjusted PR (Cl95\%) } & \multirow[t]{3}{*}{$p^{* *}$} \\
\hline & Yes $(n=17)$ & No $(n=314)$ & & & & \\
\hline & $(5.1 \%)$ & $(94.9 \%)$ & & & & \\
\hline \multicolumn{7}{|l|}{ Distal Level } \\
\hline \multicolumn{7}{|l|}{ Age group (years) } \\
\hline$\leq 15$ & 5.9 & 2.0 & $2.89(0.44-18.94)$ & 0.268 & & \\
\hline $16-19$ & 23.5 & 21.0 & $1.14(0.38-3.41)$ & 0.805 & & \\
\hline $20-34$ & 64.7 & 69.4 & 1.00 & & & \\
\hline$\geq 35$ & 5.9 & 7.6 & $0.76(0.10-5.55)$ & 0.791 & & \\
\hline \multicolumn{7}{|l|}{ Schooling (years) } \\
\hline$<4$ & 5.9 & 5.4 & $1.08(0.15-7.76)$ & 0.934 & & \\
\hline$\geq 4$ & 94.1 & 94.6 & 1.00 & & & \\
\hline \multicolumn{7}{|c|}{ Monthly family income (\$) } \\
\hline$<1 \mathrm{MW}$ & 18.8 & 6.3 & $0.99(0.99-0.99)$ & 0.033 & $2.45(0.64-9.28)$ & 0.186 \\
\hline$\geq 1 \mathrm{MW}$ & 81.2 & 93.7 & 1.00 & & & \\
\hline No information & 11 & 1 & & & & \\
\hline \multicolumn{7}{|l|}{ Stable union } \\
\hline No & 11.8 & 20.4 & $0.53(0.12-2.28)$ & 0.399 & & \\
\hline Yes & 88.2 & 79.6 & 1.00 & & & \\
\hline \multicolumn{7}{|c|}{ Working outside the home } \\
\hline No & 94.1 & 69.7 & $0.15(0.02-1.14)$ & 0.067 & $0.14(0.02-0.75)$ & 0.022 \\
\hline Yes & 5.9 & 30.3 & 1.00 & & & \\
\hline \multicolumn{7}{|l|}{ Intermediate Level } \\
\hline \multicolumn{7}{|l|}{ NCDs } \\
\hline Yes & 17.6 & 24.7 & $0.66(0.19-2.26)$ & 0.516 & & \\
\hline No & 82.4 & 75.3 & 1.00 & & & \\
\hline No information & 2 & & & & & \\
\hline \multicolumn{7}{|l|}{ Smoking habit } \\
\hline Yes & 11.8 & 7.6 & $1.56(0.37-6.48)$ & 0.538 & & \\
\hline No & 88.2 & 92.4 & 1.00 & & & \\
\hline \multicolumn{7}{|l|}{ Alcoholism Habit } \\
\hline Yes & 5.9 & 13.4 & $0.41(0.05-3.07)$ & 0.391 & & \\
\hline No & 94.1 & 86.6 & 1.00 & & & \\
\hline No information & 1 & & & & & \\
\hline
\end{tabular}

*Poisson's Bivariate Regression Test;** Poisson Multivariate Regression Test; RP=Prevalence ratio; CI95\%=Confidence Interval; Adjusted at the intermediate level for monthly family income $\leq 1$ minimum wage, work outside the home, overweight and inadequate caloric intake; SGA = Small for gestational age; STDs = Sexually Transmitted Diseases;MW = minimum wage. 
Table 1

conclusion

Association between independent variables and small for gestational age in the public health system of Maceió, Alagoas, Brazil, 2014.

\begin{tabular}{|c|c|c|c|c|c|c|}
\hline \multirow[t]{3}{*}{ Variables } & \multicolumn{2}{|c|}{ SGA } & \multirow[t]{3}{*}{ Gross PR (C195\%) } & \multirow[t]{3}{*}{$p^{*}$} & \multirow[t]{3}{*}{ Adjusted PR (Cl95\%) } & \multirow[t]{3}{*}{$p^{* *}$} \\
\hline & Yes $(n=17)$ & No $(n=314)$ & & & & \\
\hline & $(5.1 \%)$ & $(94.9 \%)$ & & & & \\
\hline \multicolumn{7}{|l|}{ Intermediate Level } \\
\hline \multicolumn{7}{|l|}{ STDs } \\
\hline Yes & 5.9 & 1.3 & $4.07(0.66-25.14)$ & 0.130 & $4.23(0.39-45.76)$ & 0.234 \\
\hline No & 94.1 & 98.7 & 1.00 & & & \\
\hline \multicolumn{7}{|c|}{ Current nutritional status } \\
\hline Low weight & 5.9 & 18.2 & $0.29(0.03-2.18)$ & 0.231 & & \\
\hline Eutrophy & 35.3 & 41.8 & 1.00 & & & \\
\hline Overweight & 58.8 & 40.0 & $2.07(0.80-5.32)$ & 0.129 & $1.72(0.63-4.65)$ & 0.285 \\
\hline No information & 1 & & & & & \\
\hline \multicolumn{7}{|c|}{ Inadequate food intake } \\
\hline Energy (kcal/day) & 64.7 & 80.3 & $0.47(0.18-1.23)$ & 0.127 & $0.50(0.15-1.59)$ & 0.243 \\
\hline Protein & 82.4 & 80.3 & $1.14(0.33-3.85)$ & 0.833 & & \\
\hline Lipid & 70.6 & 61.5 & $1.47(0.53-4.09)$ & 0.455 & & \\
\hline Carbohydrates & 0.0 & 0.3 & -------- & ------ & & \\
\hline \multicolumn{7}{|l|}{ Proximal Level } \\
\hline \multicolumn{7}{|l|}{ Way of delivery } \\
\hline Caesarean & 52.9 & 42.0 & $1.51(0.59-3.83)$ & 0.380 & & \\
\hline Vaginal & 47.1 & 58.0 & 1.00 & & & \\
\hline
\end{tabular}

*Poisson's Bivariate Regression Test; ** Poisson Multivariate Regression Test; RP=Prevalence ratio; CI95\%=Confidence Interval; Adjusted at the intermediate level for monthly family

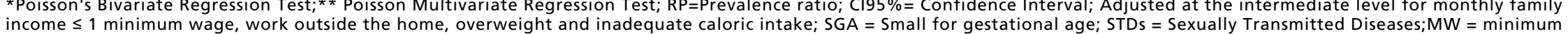
income $\leq 1$ minimum wage, work outside the home, overweight and inadequate caloric intake; SGA = Small for gestational age; STDs = Sexually Transmitted Diseases;MW = minimum
wage. 
home tend to perceive themselves as are more capable as mothers and have better physical and mental health when compared to those considered as housewives. 18

In this study, only $1 / 3$ of the pregnant women worked outside the home. When the state of Alagoas was verified, it is observed that in $2015,52.2 \%$ of the total population worked formally. Among those who work, it is observed that work remains centered as a man's role. In 2010, 35.8\% of women aged 25 to 29 years worked outside the home in the state of Alagoas. 19,20

On the other hand, in the present study there was no association between the birth of SGA and other socioeconomic characteristics (income, schooling, age, marital status), which may be justified by the fact that all children were born to mothers accompanied by SUS. Thus, the population is similar in this regard, and may have influenced the association. However, in a study carried out in a public hospital in São Paulo, a prevalence of $11.4 \%$ and $9.9 \%$ of PIG infants in women over 40 years and between 20 40 years of age respectively was observed.21 Regarding the study carried out in São Paulo, it was observed that the level of maternal schooling of four to seven years was associated with SGA births.7 In relation to income, another study carried out in Pelotas (RS) reported that families that had monthly income $<1$ minimum wage were more likely to have SGA infants $(\mathrm{OR}=8.81) .14$

The presence of STDs and non-communicable diseases (NCDs), conditions with low frequencies in the pregnant women of this study, were also not associated to the birth of SGA, contradicting the findings of another study that found association between the presence of hypertensive disorders of pregnancy and syphilis with SGA birth. ${ }^{7}$ On the other hand, the fact that the women in this study were followed up at Basic Health Units (BHUs), where the care is directed to pregnancies at habitual risk, may justify the low frequency of these diseases in this group.

When food consumption was evaluated, the association between energy intake and macronutrient intake with the outcome variable was not observed in this study, contrary to the findings of a study conducted in the United States that evaluated the association of protein consumption in pregnancy with birth weight found that women with high protein intakes had significantly higher birth weight infants compared to those whose protein intake was lower.22 It is noteworthy that in the present study high frequencies of inadequate caloric and proteins intake were found, and that other studies have shown that this situation triggers maternal and fetal complications such as insufficient or excessive gestational weight gain, heart disease, gestational diabetes mellitus, fetal growth restriction, prematurity, and low birth weight. 23

Although known to be variables that directly influence birth weight, 18 in this study, the child's gender and gestational age at birth were not variables included in the proposed hierarchical model, because the INTERGROWTH-21st 4 curve was used for classification of the birth weight that already considers in its classification the gestational age at birth and the sex of the child. Teixeira et al. ${ }^{7}$ demonstrated that the SGA birth was associated with the female sex, being born with this sex was associated with 1.69 times more chance of being SGA when compared to the male sex. Contradicting these findings, a survey conducted in Viçosa-MG found that males were associated with a higher risk of SGA (1.6 times higher) than females $(\mathrm{OR}=1.59) .24$

Regarding lifestyle, in this study, a significant percentage of pregnant women reported using cigarettes and alcohol, despite the absence of association between these variables and the birth of SGA. Important fetal repercussions (e.g. fetal growth restriction, preterm birth, infant mortality) are already well established in literature 25 as being due to the use of alcoholic beverages and smoking habits in pregnancy, depending directly on the amount and gestational age in which they were consumed.

In a prospective cohort study performed in the prenatal service in Japan, it was observed that $11.1 \%$ of SGA infants were children of women who ingested alcoholic drinks during pregnancy, compared to $7.8 \%$ in those who did not ingest, although these findings were not statistically different. ${ }^{26}$ In another study, when smoking was observed, using data from the same Japanese cohort, it was observed higher rates of SGA in women who smoked during pregnancy (18\%), when compared to the other categories. However, women with a smoking habit only in the first trimester had a lower rate than those who did not smoke, 4.2 versus $7.6 \%$ respectively. 27

In the present study, $42.6 \%$ of the children were born via cesarean delivery, contrary to the $10 \%$ and $15 \%$ recommended by the WHO. 28 Reis et al. ${ }^{29}$ in a study involving a retrospective analysis of secondary data records, stated that cesarean delivery increased the odds of an unfavorable neonatal outcome. Additionally, it is known that, when compared to normal delivery, the chance of severe maternal morbidity rises 2 -fold among women submitted to intrapartum caesarean section and 2.3 times in the 
case of elective caesarean section. The latter situation, in addition to prolonging hospital stay, is associated with higher morbidity and mortality after discharge. 30

As limitations in this study it is possible to emphasize the cross-sectional study, which makes it difficult to reach conclusions between causes and effects, as well as the fact that the sample is representative only for the Maceió city. Additionally, the authors consider that the lack of studies conducted in Brazil, using the new INTERGROWTH-21st 4 curves in the SGA classification, limited the comparison of the results found.

In the present study, the frequency of SGA in a capital city of Northeast Brazil was low, and the fact that the mother worked outside the home proved to be a protective factor for this condition. In the context of neonatal care, it is necessary to adequately classify SGA newborns through standardized reference curves, in this sense it is important to use a more representative classification of our population. It is necessary to carry out national studies, in the different regions of Brazil, that evaluate the prevalence of SGA by INTERGROWTH-21 ${ }^{\text {st }}$, and also of longitudinal studies that point out the determinants of this situation and collaborate for the implementation of specific health care policies for this target population, with the intention of contributing to the reduction of risks of morbimortality, promoting the adequate growth and development of these newborns.

\section{References}

1. Victora CG, Adair L, Fall C, Hallal PC, Martorell R, Richter $\mathrm{L}$ et al. Maternal and child undernutrition: consequences for adult health and human capital. Lancet. 2008; 371 (9609): 340-57.

2. Bocca-Tjeertes IFA, Kerstjens JM, Reijneveld SA, Winter AF, Bos AF. Growth and predictors of growth restraint in moderately preterm children aged 0 to 4 years. Pediatrics. 2011; 128 (5): e1187-94

3. Grisaru-Granovsky S, Reichman B, Lerner-Geva L, Boyko V, Hammerman C, Samueloff A, Schimmel MS, Israel Neonatal Network. Mortality and morbidity in preterm small-for-gestational-age infants: a population-based study. Am J Obst Gynecol. 2012; 206 (2): 150-e7.

4. Villar J, Ismail LC, Victora CG, Ohuma EO, Bertino E, Altman DG, Lambert A, Papageorghiou AT, Carvalho M, Jaffer YA, Gravett MG, Purwar M, Frederick IO, Noble AJ, Pang R, Barros FC, Chumlea C, Bhutta ZA, Kennedy SH; International Fetal and Newborn Growth Consortium for the 21 st Century (INTERGROWTH-21st). International standards for newborn weight, length, and head circumference by gestational age and sex: the Newborn CrossSectional Study of the INTERGROWTH-21st Project. Lancet. 2014; 384 (9946): 857-68.

5. Moore KA, Simpson JA, Wiladphaingern J, Min AM, Pimanpanarak M, Paw MK, Raksuansak J, Pukrittayakamee S, Fowkes FJI, White NJ, Nosten F, McGready R. Influence of the number and timing of malaria episodes during pregnancy on prematurity and small-for-gestational-age in an area of low transmission. BMC Med. 2017; 15 (1); 117-29.

6. Tuzun F, Yucesoy E, Baysal B, Kumral A, Duman N, Ozkan H. Comparison of INTERGROWTH-21 and Fenton growth standards to assess size at birth and extrauterine growth in very preterm infants. J Matern Fetal Neonatal Med. 2017; 30 (1): 1-12

7. Teixeira MPC, Queiroga TPR, Mesquita MA. Frequência e fatores de risco para o nascimento de recém-nascidos pequenos para idade gestacional em maternidade pública. Einstein (16794508). 2016; 14 (3): 317-23.
8. Atalah SE, Castilho LC, Castro Santoro R, Aldea PA. Propuesta de un nuevo estándar de evaluación nutricional en embarazadas. Rev Med Chile. 1997; 125 (12): 1429-36.

9. Rasmussen KM, Yaktine AL; Institute of Medicine. National Research Council. Committee to Reexamine IOM Pregnancy Weight Guidelines. Weight gain during pregnancy: reexamining the guidelines. Washington: National Academies Press; 2009.

10. International Life Science Institute. Usos e aplicações das Dietary Reference Intakes - DRIs. São Paulo: ILSI/ SBAN; 2001. 47p. 10.

11. Dietary Reference Intakes for Vitamin A, Vitamin K, Arsenic, Boron, Chromium, Copper, Iodine, Iron, Manganese, Molybdenum, Nickel, Silicon, Vanadium, and Zinc. Washington: National Academy Press; 2002.

12. OMS (Organização Mundial da Saúde). OMS public health aspects of low birth weight. Tech Rep Series, n. 217. Geneve; 1961.

13. Monteiro CA, De Freitas ICM. Evolução de condicionantes socioeconômicas da saúde na infância na cidade de São Paulo (1984-1996). Rev Saúde Pública. 2000; 34 (6): 8-12.

14. Zambonato AMK, Pinheiro RT, Horta BL, Tomasi E. Fatores de risco para nascimento de crianças pequenas para idade gestacional. Rev Saúde Pública. 2004; 38 (1): 24-9.

15. Santos EMF, Amorim LP, Costa OLN, Oliveira N, Guimarães AC. Perfil de risco gestacional e metabólico no serviço de pré-natal de maternidade pública do Nordeste do Brasil. Rev Bras Ginecol Obstet. 2012; 34 (3): 102-6.

16. Nobile CGA, Rafaele G, Altomare C, Pavia M. Influence of maternal and social factors as predictors of low birth weight in Italy. BMC Public Health. 2007; 7 (1): 192-201.

17. Fiorin PC, Oliveira CT, Dias ACG. Percepções de mulheres sobre a relação entre trabalho e maternidade. Rev Bras Orientaç Prof. 2014; 15 (1): 25-35.

18. D'Affonseca SM, Cia F, Barham EJ. Trabalhadora feliz, mãe feliz? Condições de trabalho que influenciam na vida familiar. Psicol. Argum. 2014; 32 (76): 129-38. 
19. IBGE (Instituto Brasileiro de Geografia e Estatística). Pesquisa Nacional de Saúde: 2013: acesso e utilização dos serviços de saúde, acidentes e violências: Brasil, grandes regiões e unidades da federação; 2015.

20. IBGE (Instituto Brasileiro de Geografia e Estatística) Censo IBGE. v. 23, 2010. [acesso em 20 de ago 2017] Disponível em: $<$ http://www. censo2010. ibge. gov. br

21. Canhaço EE, Bergamo AM, Lippi UG, Lopes RGC Resultados perinatais em gestantes acima de 40 anos comparados aos das demais gestações. Einstein (16794508). 2015; 13 (1): 58-64.

22. Sloan NL, Lederman SA, Leighton J, Himes JH, Rush D. The effect of prenatal dietary protein intake on birth weight. Nutr Res. 2001; 21 (1-2): 129-39.

23. Rasmussen KM, Catalano PM, Yaktine AL. New guidelines for weight gain during pregnancy: what obstetrician/gynecologists should know. Curr Opin Obst Gynecol. 2009; 21 (6): 521-26

24. Freitas BAC, Lima LM, Lopes MEM, Carlos CFLV, Priore SE, Franceschini SCC. Comparison of two growth curves for detecting small-for-gestational-age newborns. Rev Bras Saúde Mater Infantil. 2016; 16 (1): 21-7.

25. Santiago SE, Park GH, Huffman KJ. Consumption habits of pregnant women and implications for developmental biology: a survey of predominantly Hispanic women in California. Nutr J. 2013; 12 (1):1-14.
26. Miyake Y, Tanaka k, Okubo H, Sasaki S, Arakawa M. Alcohol consumption during pregnancy and birth outcomes: the Kyushu Okinawa Maternal and Child Health Study. BMC Pregnancy Childbirth. 2014; 14 (1): 79-86.

27. Miyake Y, Tanaka K, Arakawa M. Active and passive maternal smoking during pregnancy and birth outcomes: the Kyushu Okinawa Maternal and Child Health Study. BMC Pregnancy Childbirth. 2013; 13 (1): 157-65.

28. Organização Mundial de Saúde. Declaração da OMS sobre Taxas de Cesáreas. [acesso em 20 ago 2017]. Disponível em:< http://apps.who.int/iris/bitstream/10665/161442/3/ WHO_RHR_15.02_por.pdf.

29. Reis ZSN, Lage EM, Aguiar RALP, Gaspar JS, Vitral GLN, Machado EG. Associação entre risco gestacional e tipo de parto com as repercussões maternas e neonatais. Rev Bras Ginecol Obstet. 2014; 36 (2): 65-71.

30. Villar J, Carroli G, Zavaleta N, Donner A, Wojdyla D, Faundes A, Velazco A, Bataglia V, Langer A, Narváez A, Valladares E, Shah A, Campodónico L, Romero M, Reynoso S, Pádua KS, Giordano D, Kublickas M, Acosta A, World Health Organization 2005 Global Survey on Maternal and Perinatal Health Research Group. Maternal and neonatal individual risks and benefits associated with caesarean delivery: multicentre prospective study. BMJ. 2007; 335 (7628): 1025 .

Received on October 10, 2017

Final version presented on February 16, 2018

Approved on July 18, 2018 